\title{
Europa, que futuro?
}

\author{
Europe, what Future? \\ Marta Nunes DA Costa \\ UFSC Brasil \\ nunesdacosta77@gmail.com
}

\section{Resumo}

Num momento em que o futuro da Europa parece estar suspenso, o texto de Tarizzo convida-nos a refletir sobre as condições de possibilidade para levar a cabo o projeto europeu. Neste artigo oferecemos uma leitura crítica acerca das dimensões económica e política europeias e da relação entre elas. O nosso objectivo é mostrar que o desafio na Europa hoje não é só de repensar a relação entre economia, por um lado, e democracia, por outro, mas também buscar as condições para a reinvenção da própria política.

Palavras-chave: democracia, cidadania europeia, mobilidade, neoliberalismo, solidariedade.

\begin{abstract}
As Europe's future seems suspended, Tarizzo's text invites us to reflect upon the conditions of possibility of leading the original European project. In this paper we offer a critical account on the economic and political European dimensions, and its relationship. Our goal is to show that the challenge today in Europe is not only to reconceptualize the relationship between economy and democracy; rather, it is imperative to look for new conditions for the reinvention of politics.

Keywords: democracy, European citizenship, mobility, neoliberalism, solidarity.

O texto de Tarizzo corrobora a tendência que se verifica nos dias de hoje, mas que nem por isso deixa de ser urgente, a saber, a tendência de refletir sobre o futuro e condições de possibilidade para levar a cabo o projeto europeu. Com efeito, vivemos hoje um tempo de grandes questões; um tempo que resistindo a qualquer possível "eterno retorno" ou repetição da história em configurações variadas, se apresenta como radicalmente distinto do passado. Esta distinção radical não se deve à diferen-
\end{abstract}


ciação conceptual apenas. Os conceitos com que trabalhamos são os mesmos, e isso é com certeza parte do problema. Mas a forma como esses conceitos se adequam (ou não) à realidade que tentamos explicar, obrigam-nos, por um lado, a rever criticamente a nossa história e por outro, a redefinir esses próprios conceitos assim como os parâmetros da discussão.

O futuro da Europa parece suspenso. Essa suspensão deve-se a um conjunto de factores que caracterizam o nosso histórico a priori (Foucault), ou seja, que determinam especificamente este momento na história como o nosso momento e não de outros. Estes factores são de diversas ordens, nomeadamente, da ordem económica, social e política. Neste artigo quero concentrar-me na ordem económica por um lado, e na ordem política por outro. A primeira, por se prender claramente com a qualidade do tipo de crise que hoje se experiencia na Europa e no Mundo; a segunda por nos obrigar a questionar as condições do presente e a imaginar um futuro possível onde a Europa resista às crises e se afirme como projeto político único e singular no Mundo. Assim, enquanto que considerações sobre a ordem económica ajudar-nos-ão a caracterizar a especificidade do nosso tempo, considerações sobre a ordem política forçar-nos-ão a projetar com visão e imaginação um futuro viável e sustentável da Europa, reconfigurando o seu posicionamento num contexto global mais vasto. Serão feitas considerações sobre a ordem social a título exemplar, sobretudo na forma como manifestações sociais podem agir como espelho (por vezes deturpado) do que se passa nas outras ordens.

Relativamente à ordem económica, percebemos que o projeto inicial de uma Europa como espaço privilegiado para a livre circulação de bens, serviços, capitais e pessoas, implicaria como suas condições suficientes para sucesso, uma conceptualização e redefinição dos espaços - nacionais e supranacionais- e sua regulamentação. A ideia de que seria possível criar um grande espaço comum europeu (e aqui espaço refere-se ao entendimento limitado de "mercado") reforçado por uma moeda única, mostra-se hoje insuficiente para garantir qualquer espécie de unidade europeia. Com efeito, a construção do projeto europeu parece ter sido movida pela conviç̧ão de que a ordem económica poderia manter-se independente das outras ordens -social, política e cultural-como se esta fosse autónoma, como se esta não refletisse ela mesma um conjunto de crenças, princípios e orientações que a transcendem enquanto tal. Esse, a meu ver, tem sido o maior erro, a saber, a criação e promoção de uma separação de ordens -sobretudo da ordem económica e política- e a afirmação da supremacia da primeira sobre a segunda. As tensões aparecem a partir do momento em que este mesmo projeto de "mercado livre" tem como sua condição de possibilidade a adopção da democracia como modelo político. Mas já de início, uma questão fundamental se levanta: que relação deve existir entre a ordem política e a ordem económica? E como deve esta relação manter-se e redefinir-se num contexto marcadamente democrático?

Muitos outros problemas se levantam com a análise do conceito de democracia. De que tipo de democracia estamos, afinal, a falar? Há tantos modelos quantas ins- 
tanciações democráticas, basta olhar para a diversidade de experiências políticas europeias, desde regimes presidencialistas, a federações, entre outros. Não é aqui o lugar para fazer este levantamento; no entanto, importa realçar o facto de que cada modelo é movido por certas premissas, e que a diferença entre estas origina atualizações bastante diferentes. Uns podem apostar mais no ideal de igualdade, como princípio fundador e regulador democrático; outros podem apostar mais no ideal de liberdade individual; outros ainda, no ideal de autonomia; e por aí em diante. No entanto, comum a toda a variedade de atualizações democráticas está a crença de que a democracia se baseia no princípio de autonomia enquanto auto-governação; se edifica sobre os princípios de igualdade e liberdade, e traduz uma relação entre representantes e representados.

Apesar desta raiz comum, importa não esquecer que o desenvolvimento da democracia traduz ele próprio uma história de trajetórias distintas: por um lado, o alargamento e redefinição do conceito de cidadania ativa, isto é, a noção de que cada pessoa tem apenas um voto. Isto deu origem à universalização dos direitos eleitorais e liberdades civis e à sua extensão para lá do ato eleitoral (Green, 2012). Por outro lado, o progresso da democracia também significou a assimilação do espírito de acumulação capitalista. Aqui, mais do que a transversalidade de igualdade, torna-se visível a abertura de espaços para constituição de formas oligárquicas de capitalismo, e consequentemente, de governação. A partir do momento em que se aceita que o mercado rege tudo, ou seja, que tudo se deve submeter às leis (mesmo que invisíveis) do mercado, toda e qualquer pretensão de igualdade política, princípio básico da democracia, se encontra em cheque correndo o risco de deixar de fazer sentido. Dito por outras palavras, a partir do momento em que a ordem económica assimila, engole e absorve a ordem política, a democracia fica suspensa.

Preliminarmente podemos já dizer que o projeto europeu está suspenso e permanecerá suspenso enquanto a democracia estiver suspensa.

Esta suspensão acontece porque quando falamos de democracia falamos de direitos e deveres que cidadãos possuem dentro de um espaço especificamente político, mas também social, cultural e económico. Cidadania é assim um conceito chave para se pensar a democracia e para se pensar a Europa. Mas que tipo de cidadania encontramos hoje? Como Tarizzo bem nos alerta, o problema é que os indivíduos vivem hoje em dois espaços políticos: o espaço da nação e o espaço da União Europeia. Assim, os indivíduos pertencem a duas comunidades em simultâneo: pertencem, por um lado, ao seu "povo" baseado num conceito de identidade nacional; e pertencem por outro lado a um "povo" imaginário que está ainda a construir-se, um povo "europeu". ${ }^{1}$ Mas que "povo" europeu é este? Não há um "povo" europeu,

\footnotetext{
${ }^{1}$ Habermas diz "[...] the foundation of the European Union can be conceived retrospectively as thoug the citizens involved (or their representatives) were Split into two personae from the beginninf; in that case every person as a European citizen in the constitution-founding process encounters herself, as it
} 
e mesmo a promessa da sua construção está hoje em cheque. Esse povo não existe não só porque não existem cidadãos europeus, como diz Tarizzo, mas também e sobretudo, porque mesmo os cidadãos que existiriam a nível do Estado-nação veem o seu sentido ontológico e as suas condições de efetivação condicionadas e ameaçadas. Assim, o problema é ainda mais grave do que Tarizzo anuncia. Vejamos.

A cidadania traduz uma relação entre o indivíduo / cidadão e a nação soberana. É por existir esta relação que se definem direitos e deveres; que se criam instituições que os garantem e legitimam. A relação entre representantes e representados baseiase na premissa básica de qualquer democracia, a saber, a premissa da eleição em tempos regulares. $\mathrm{O}$ cidadão, independentemente do conjunto de direitos que possa ter, afirma-se pelo seu poder de votar nas eleições dentro do Estado-nação a que pertence. Tradicionalmente, a cidadania era definida com base numa pertença sanguínea ou cultural. ${ }^{2}$ A União Europeia trata os cidadãos dos Estados membros como cidadãos desses estados, mas ainda não como cidadãos europeus. Se por um lado se garantem as condições para o livre fluxo dos indivíduos dentro do espaço europeu, por outro, esse fluxo tem um custo político extremamente elevado, na medida em que "aqueles que exercitam o seu direito de livre movimento, de uma forma ou de outra, acabam sendo privados em relação a todas as eleições não cobertas pelo artigo 22 TFEU, a não ser que escolham a custosa via de adquirir a cidadania do estado que os acolhe ou se têm sorte de ter a cidadania de um dos Estados Membros que não imponham condições sobre o exercício de direitos de voto externos."

É no mínimo curioso que a questão da mobilidade de cidadãos de Estados membros na União Europeia seja sempre remetida para as margens do debate político e raramente mereça atenção nos media ou debate público. Isto toca no centro de uma das atuais limitações do projeto europeu, a saber, de que na Europa se pode falar de hospitalidade europeia, mas ainda não de cidadania europeia. Ora, ao promover discursos sobre hospitalidade, a Europa está a lutar contra si mesma; em vez de promover medidas que contribuam para a criação de um corpo político real e transnacional, alimenta a construção de espaços não-identitários, logo, que dificilmente poderão convergir. Enquanto permanecermos nesta Europa da hospitalidade, temos apenas uma "europa das nações", como diz Tarizzo. Isto é claramente insuficiente. Em primeiro lugar, porque sem a criação real e efetiva de uma cidadania europeia, a partir do momento em que os cidadãos de Estados membros exerçam o seu direito

were, as a citizen of an already constituted national people." Em J. Habermas, The Crisis of the European Union - a Response, trad. de C. Cronin, Malden MA, Polity Press, 2012, p. 38.

${ }^{2} \mathrm{M}$. Nunes da Costa, "How participatory budgeting changes the meaning and practices of citizenship" na Revista Internacional de Filosofia da Moral [International Journal of Moral Philosophy] - Ethica 12, 2013, pp. 301-320.

${ }^{3}$ J. Shaw, "EU Citizenship and the Edges of Europe" in The Europeanisation of Citizenship in the Successor States of the Former Yugoslavia, Working Paper 2012/19, University of Edinburgh, 2012, p. 89 . 
de mobilidade, esses mesmos cidadãos perdem na prática muitos dos seus direitos. O cenário do mercado de trabalho europeu exemplifica o trade-off que os cidadãos estão dispostos a fazer, a saber, ter emprego muitas vezes em detrimento da sua autonomia política, mas também cultural, social e económica. Em segundo lugar, se a europa da hospitalidade se baseia no princípio da dignidade, então os critérios para a construção de uma cidadania europeia têm de mudar. Não podem mais ser, ou apenas ser, o ius soli e ius sanguinis, pelo contrário, uma cidadania assente na hospitalidade deve regular-se pelo princípio de ius laboris. Assim, o critério para cidadania não seria mais a família, laços de sangue ou laços de terra, mas sim laços laborais. O mercado laboral estaria assim no centro de uma conceptualização de cidadania europeia. Em terceiro lugar, esse novo conceito de cidadania vem alterar a dinâmica das relações entre cidadãos e Estados-membros e cidadãos e Europa como um todo. Com este conceito altera-se também a relação entre representantes e representados, a forma como as reivindicações se formam e se propagam, a forma como a mobilização social acontece, a forma como os sindicatos se redefinem, a forma como a política acontece.

Alguns, porém, objectam dizendo que o problema da mobilidade é um falso problema no sentido em que afecta apenas 1 ou $2 \%$ da população total da Europa e que portanto, não deve ser critério para se pensar a reconfiguração dos significados de uma cidadania europeia. Embora a objecção esteja correta afirmando que as pessoas afectadas pelo direito à mobilidade são uma minoria, está também incorreta na medida em que seria um erro pensar que por serem minoria não merecem preocupação, destaque, e defesa dos seus direitos. Enquanto exercendo os seus direitos de mobilidade os cidadãos europeus vêem-se de facto privados de direitos que podem ser relevantes. Porém, estaríamos a perder o foco central da questão ao centrarmonos demasiado na dicotomia entre Europa da hospitalidade e Europa dos cidadãos. Esta dicotomia apenas revela uma dicotomia mais grave e profunda na forma como a Europa se entende a si própria e se projeta para si mesma, reflexivamente, e para o exterior. $\mathrm{O}$ atual cenário de crise financeira afetando vários Estados-Membros vem desvelar a verdadeira natureza da crise - não apenas económica, mas principalmente política.

Assistimos à propagação de manifestações massivas de cidadãos em quase todos os países europeus; essas manifestações reclamam o corte das despesas dos Estados, sobretudo afetando de forma incisiva a saúde e a educação, mas não se limitando a estas esferas. Os tempos de austeridade que se vivem na Europa desde 2008 revelam algo que já se sabia, mas que se ia evitando confrontar, a saber, a falta de coragem para dar passos no sentido de uma coordenação política mais eficaz, e a necessidade de definir a Europa enquanto tipo específico de constituição política. Afinal, o que é a Europa? Um projeto meramente económico? Ficou claro que a economia manifesta os sintomas mas não possui em si mesmo a cura para a doença; a cura só pode ser encontrada no âmbito da esfera política. Assim, caminhamos para uma federação 
de Estados-membros, à semelhança dos Estados Unidos ou do Brasil, ou para outro tipo de coordenação interestadual ainda não experimentada na história? Por outras palavras, como sair da crise numa Europa que está refém das divisões que ela mesma tentou superar?

Penso que o que fica claro com os tempos presentes é que o projeto europeu só pode sair reforçado das crises atuais se a democracia sair igualmente reforçada. Enquanto que os processos políticos a nível nacional se mantém cruciais para definir cada estado como mais (ou menos) democrático, urge criar novos espaços democráticos a nível da União. Como diz Habermas, "[o] principal desafio a nível institucional é, no entanto, recuperar o igual posicionamento e relação simétrica na distribuição de funções e competências legislativas que conferimos de forma reconstrutiva aos povos Europeus e aos cidadãos europeus enquanto sujeitos fundadores da constituição."4

Esses espaços não se esgotam no existente parlamento europeu, nem na comissão (que poucos ou nenhuns processos de responsabilização vis-à-vis os cidadãos tem); é preciso encontrar um equilíbrio entre as competências do Conselho Europeu e do Parlamento a nível de todas as esferas políticas, ${ }^{5}$ mas é preciso ir mais longe. Um dos grandes problemas que urge confrontar é o abismo que existe entre cidadãos (no seu duplo sentido de pertença a uma comunidade nacional e pertença a uma comunidade europeia) e as elites políticas, ou seja, a total assimetria na distribuição de poderes - quer na influência na constituição de uma agenda política, quer na participação efetiva dos cidadãos sobre essa agenda já constituída por uma elite. Este abismo só pode ser ultrapassado se acontecerem duas coisas. Por um lado, do ponto de vista normativo, é preciso reconceptualizar os meios escolhidos pela e na Europa para que a Europa se pense a si própria e se construa politicamente. Por outro lado, do ponto de vista prático é preciso traduzir essa reconceptualização na criação de pontes de contacto entre os cidadãos e instituições representativas, e isto passa pela criação de novos mecanismos participativos em todos os Estados-Membros.

Relativamente ao primeiro, as funções e poderes de cada instituição têm de ser clarificadas e eventualmente reforçadas ou alteradas. ${ }^{6}$ Isto implica que as elites políticas que têm gerido ou administrado (muitas vezes com falta de orientação e visão política) a construção europeia têm de mudar de atitude e de comportamento. Se não queremos que a Europa se converta num "arranjo para exercer um tipo de regra pósdemocrática e burocrática" tornando-se assim no oposto do que o Projeto Europeu supostamente devia ser, então é preciso pensar uma cidadania europeia não só através da categoria de hospitalidade, mas sobretudo através da categoria de solidarieda-

\footnotetext{
${ }^{4}$ Habermas, op. cit., p. 43.

${ }^{5}$ Habermas, op. cit., p. 43.

${ }^{6}$ Por exemplo, é no mínimo estranho que o Conselho Europeu tenha aparentemente poder político mas não as suas decisões não tenham força legal. Neste seguimento ver Habermas, op. cit., p. 44.

${ }^{7}$ Habermas, op. cit., p. 52.
} 
de e dignidade humana. Em vez de cultivar divisões entre uma comunidade que já é suficientemente diversa - linguística e culturalmente - é necessário criar princípios reguladores de ação institucional transnacional que possam garantir os direitos fundamentais dos cidadãos europeus. ${ }^{8}$ A Europa só é sustentável enquanto projeto se se basear na solidariedade entre os povos e no compromisso com princípios verdadeiramente democráticos - tais como igualdade política e liberdade de expressão - não podendo nunca ser remetidos para uma segunda ordem de prioridades. A Europa só poderá ser resgatada desta crise se se reinventar através de um novo ou renovado conceito de cidadania europeia, baseada no compromisso com direitos fundamentais, transversais a todas as culturas europeias. Por outras palavras, a Europa só pode salvar-se se colocar as prioridades na ordem certa.

Enquanto a Europa estiver refém de "políticas" neoliberais de que "políticas" só têm mesmo o nome, a Europa está destinada ao fracasso porque o neoliberalismo é incompatível com a democracia, e com a política. A ideologia neoliberal que tem sido apresentada como única ideologia válida disponível (assimilando todas aquelas à que ela se queiram opor) traduz o lado mais negro da acumulação de capital que nada tem para além de si mesmo; onde já não se cria valor mas apenas se reproduz e muda de mãos. A Europa perde competitividade de ano para ano; muitos dos seus países estão à venda a preço de saldo, colocando a soberania dos mesmos em questão - afinal, quão soberano pode ser um país que deixa de possuir os próprios bens fundamentais como água, energia, transportes? Tudo em nome da competitividade no mercado e da estabilidade orçamental. Mas em todo o discurso, pouco ou nada se diz acerca das pessoas. As pessoas, os cidadãos de uma europa em construção, que são forçados a perder direitos em nome de uma economia competitiva -como se baixos salários pudessem traduzir maior produtividade, e maior qualidade na produção. Sejamos realistas e sinceros- a Europa nunca poderá competir com a China nem com outros países asiáticos que pouco a pouco tomam conta dos mercados pela total ausência de uma filosofia de direitos humanos ou compromisso democrático. A Europa só poderá competir verdadeiramente com estas economias emergentes quando deixar de ser Europa, quando deixar de ser símbolo de progresso humanista, à custa de uma dolorosa aprendizagem na história; quando deixar de ser democrática. A Europa só poderá competir quando a democracia desaparecer do vocabulário e das memórias dos cidadãos e quando os cidadãos se reduzirem a meras peças de um puzzle maior de produção a grande escala. A Europa só poderá competir quando regredir na história, esquecendo tudo o que conquistou e as razões pelas quais conquistou direitos de primeira, segunda e terceira geração e quando matar de vez a política.

\footnotetext{
8 "A political integration backed by social welfare is necessary if the national diversity and the incomparable cultural wealth of the biotope "old Europe" are to enjoy any protection against becoming levelled in the midst of rapidly progressing globalization.' Em Habermas, op.cit., p. 53.
} 
O neoliberalismo convida à morte da política. Dentro dos seus Estados-nações, os cidadãos vêm muitos dos seus políticos eleitos substituídos por tecnocratas, remetendo todo o processo político eleitoral (mas não só) a mero ato rotineiro e retórico. Fora dos seus Estados-nações mas dentro da União Europeia, os cidadãos buscam um sentido de cidadania exequível e viável. Poder falar de cidadania europeia implica, antes de mais, poder falar de política na Europa. Poder falar de política na Europa implica, antes de mais, rever as prioridades e denunciar o neoliberalismo como forma errada de regular atos diplomáticos intraestaduais. Ou seja, como já mencionei, poder falar de política na Europa implica que as elites políticas mudem -não numérica mas qualitativamente, na forma de abordarem os problemas e conceptualizarem soluções. É por isso que em última análise o desafio é ainda mais profundo do que inicialmente assinalámos. Não se trata apenas de tentar saber se a Europa tem futuro, se a democracia é sustentável -nestas questões está subjacente a questão primeira, a saber, como recuperar a política?

Recuperar a política implica, antes de mais, recuperar espaços para o pluralismo. Aqui, não só as elites podem e devem desempenhar um papel catalisador na mudança de paradigma, como também os media e a sociedade civil em geral. A rejeição tout court do neoliberalismo não será fácil nem talvez possível no seu todo. No entanto, é preciso criar novos espaços para que ideologias competitivas surjam e se afirmem como alternativas viáveis ao que temos hoje. Não quero com isto dizer por exemplo que seja possível salvar o "Estado-Social" tal como o conhecemos. No entanto, se a estas ideologias competitivas criarmos mecanismos de participação cidadã reformulando o diálogo institucional, poderemos estar a abrir campo para um novo modelo de pensar e viver a democracia para lá do Estado-Nação. É pela qualidade democrática das suas instituições que a Europa se poderá demarcar no Mundo, é pelo compromisso com direitos e valores fundamentais que a Europa se poderá construir como projeto político viável no futuro, trabalhando para os cidadãos e não para a perpetuação e multiplicação do capital sem cara. Esperemos que a Europa se consiga afirmar e diferenciar pela qualidade da sua cidadania, e não pela erosão dos seus princípios reguladores. O tempo o dirá. 